\title{
Comparing methods of measuring sea-ice density in the East Antarctic
}

\author{
Jennifer K. HUTCHINGS, ${ }^{1}$ Petra HEIL, ${ }^{2,3}$ Oliver LECOMTE, ${ }^{4}$ Roger STEVENS, ${ }^{3}$ \\ Adam STEER, ${ }^{2}$ Jan L. LIESER ${ }^{3}$ \\ ${ }^{1}$ College for Earth, Ocean and Atmospheric Science, Oregon State University, Corvallis, OR, USA \\ E-mail: hutchings@coas.oregonstate.edu \\ ${ }^{2}$ Australian Antarctic Division, Kingston, Tasmania, Australia \\ ${ }^{3}$ Antarctic Climate and Ecosystems Cooperative Research Center, University of Tasmania, Hobart, Tasmania, Australia \\ ${ }^{4}$ Georges Lemaitre Centre for Earth and Climate Research (TECLIM), Earth and Life Institute (ELI), \\ Université Catholique de Louvain, Louvain-la-Neuve, Belgium
}

\begin{abstract}
Remotely sensed derivation of sea-ice thickness requires sea-ice density. Sea-ice density was estimated with three techniques during the second Sea Ice Physics and Ecosystem eXperiment (SIPEX-II, September-November 2012, East Antarctica). The sea ice was first-year highly deformed, mean thickness $1.2 \mathrm{~m}$ with layers, consistent with rafting, and 6-7/10 columnar ice and 3/10 granular ice. Ice density was found to be lower than values $\left(900-920 \mathrm{~kg} \mathrm{~m}^{-3}\right.$ used previously to derive ice thickness, with columnar ice mean density of $870 \mathrm{~kg} \mathrm{~m}^{-3}$. At two different ice stations the mean density of the ice was 870 and $800 \mathrm{~kg} \mathrm{~m}^{-3}$, the lower density reflecting a high percentage of porous granular ice at the second station. Error estimates for mass/volume and liquid/solid water methods are presented. With $0.1 \mathrm{~m}$ long, $0.1 \mathrm{~m}$ core samples, the error on individual density estimates is $28 \mathrm{~kg} \mathrm{~m}^{-3}$. Errors are larger for smaller machined blocks. Errors increase to $46 \mathrm{~kg} \mathrm{~m}^{-3}$ if the liquid/solid volume method is used. The mass/volume method has a low bias due to brine drainage of at least $5 \%$. Bulk densities estimated from ice and snow measurements along $100 \mathrm{~m}$ transects were high, and likely unrealistic as the assumption of isostatic balance is not suitable over these length scales in deformed ice.
\end{abstract}

KEYWORDS: sea ice

\section{INTRODUCTION}

Sea-ice density is a key parameter in the estimation of seaice thickness using freeboard measurements from airborne or spaceborne altimeters The density range generally used in Antarctic sea-ice thickness estimation is $900-920 \mathrm{~kg} \mathrm{~m}^{-3}$ (Giles and others, 2008; Worby and others, 2008; Zwally and others, 2008; Kurtz and Markus, 2012; Xie and others, 2012; Price and others, 2013). This is generally based upon either the Timco and Frederking (1996) review, or measurements taken in a specific location. A $10 \mathrm{~kg} \mathrm{~m}^{-3}$ uncertainty in ice density is typically assumed when estimating uncertainty in the retrieval of ice thickness from freeboard (Kwok and Cunningham, 2008; Price and others, 2014). For Ice, Cloud and land Elevation Satellite (ICESat)-based estimates of sea-ice thickness, uncertainty in ice density accounts for up to $12 \%$ of error in the thickness estimate (Kwok and Cunningham, 2008).

Sea-ice density is dependent on where the ice is in relation to the waterline, the ice type (Timco and Frederking, 1996), and temperature and salinity of the ice (Cox and Weeks, 1983). Measurements reported in the literature vary between 720 and $940 \mathrm{~kg} \mathrm{~m}^{-3}$. Densities of ice formed from frazil or columnar growth are reported as being similar (Sinha, 1984). Estimates of bulk sea-ice density over the entire ice column tend to be lower for multi-year ice than for first-year ice, due to brine drainage.

The mean density of first-year ice is often taken to be $920 \mathrm{~kg} \mathrm{~m}^{-3}$, derived by Timco and Weeks (2010). Different methodologies were used by the authors of the reports surveyed in the Timco and Weeks (2010) review, making intercomparison of the different field measurements difficult. Measurement errors and biases are not always reported, further compounding difficulties in determining mean ice density.

There are relatively few measurements taken of sea-ice density around Antarctica. To estimate mean first-year ice density, Timco and Frederking (1996) used datasets from 16 field sites. Only one of these was an Antarctic-based field study, at Lützow-Holm Bay (Urabe and Inoue, 1986). That study found relatively low values for density, $750-880 \mathrm{~kg} \mathrm{~m}^{-3}$ (Urabe and Inoue, 1986). A value of $900 \mathrm{~kg} \mathrm{~m}^{-3}$ has been taken by several studies to estimate Antarctic sea-ice thickness (e.g. Giles and others, 2008; Worby and others, 2008). That density is based upon a set of field measurements taken during summer and winter (Buynitskiy, 1967).

Other studies use information from Timco and Frederking's (1996) review, which suggests a higher mean bulk ice density of $910-920 \mathrm{~kg} \mathrm{~m}^{-3}$, though with limited sampling of sea ice in the Southern Ocean. Price and others (2014) report mean first-year ice density of $915 \mathrm{~kg} \mathrm{~m}^{-3}$ in McMurdo Sound. They report higher values of $927 \mathrm{~kg} \mathrm{~m}^{-3}$ estimated using the hydrostatic assumption over seven drillhole measurements.

It is unknown whether these values of mean bulk ice density are applicable to all the ice types and conditions found throughout the Southern Ocean. Reports of relatively low first-year ice bulk density in the Antarctic (Buynitskiy, 1967; Urabe and Inoue, 1986) and higher density (Price and others, 2014) suggest that uncertainty may be $>10 \mathrm{~kg} \mathrm{~m}^{-3}$ in the Antarctic. Increased reporting of measured ice density would provide a larger dataset from which to estimate mean 


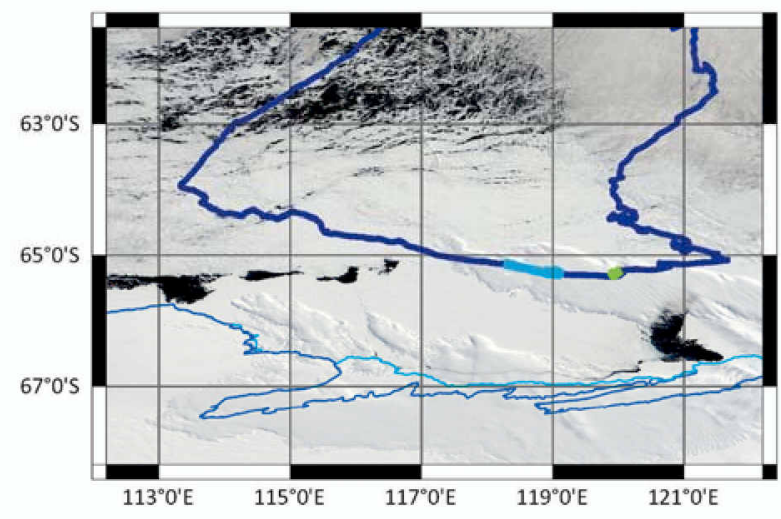

Fig. 1. Map of cruise track (thick blue line), with location of icedrifting stations 6 (green) and 7 (cyan). The tracks are overlaid on a Moderate Resolution Imaging Spectroradiometer (MODIS) truecolor image. On this image the coastline of Antarctica is shown as a light blue thin line and the ice tongues are outlined with a thin cyan line.

ice density with greater statistical confidence. In this paper we report ice density measurements obtained in the East Antarctic during the 2012 austral winter-to-spring transition. Different methods were used to measure density from adjacent ice cores and drilling transects. We take this opportunity to identify errors and biases for each of these methods.

\section{DATA DESCRIPTION}

During the second Sea Ice Physics and Ecosystem eXperiment (SIPEX-II, 14 September-14 November 2012), the R/V Aurora Australis sailed from the marginal ice zone almost to the Antarctic fast-ice edge in the region $121.5-113.5^{\circ} \mathrm{E}$. Several ice stations were conducted along the track (Fig. 1). At stations 6 (6-13 October) and 7 (19-23 October), multiple ice cores were taken adjacent to each other for the purpose of density measurements. These were processed for ice structure, temperature and salinity profiles. The cores were located close to a $100 \mathrm{~m}$ ice thickness survey line ('transect'). Along this line, snow pits were taken at 0,50 and $100 \mathrm{~m}$. An additional two pits were made at station 6 along a $100 \mathrm{~m}$ line perpendicular to the thickness transect. Snow thickness, snow/ice interface temperature, ice freeboard and total thickness were measured at $1 \mathrm{~m}$ intervals along the transects.

At two sites, one on ice station 6 close to $50 \mathrm{~m}$ on the survey line, the other on ice station 7 close to $100 \mathrm{~m}$, two ice cores were taken side by side. The ice thickness was 1.6 and $2.24 \mathrm{~m}$ at the station 6 and 7 sites respectively. The sites were chosen for being relatively level compared to surrounding ice. Of the two cores from each site, one was processed for ice structure and used for density measurement with small blocks. The other was dedicated to density measurement.

\section{ESTIMATING SEA-ICE DENSITY}

Sea-ice density measurement is notoriously difficult. A standard methodology to measure sea-ice density has not been agreed upon, and, to our knowledge, different measurement methods have not been compared in situ.

There are several methods of estimating ice density, which are reviewed by Timco and Frederking (1996). In this study we focus on comparison of three methods: the mass/volume method (following Timco and Frederking, 1996), the liquid/solid volume method and the transect method.

In taking cores to estimate ice density, care should be taken to minimize brine drainage while processing the cores. A core that is processed for temperature and cut on the ice will experience some brine drainage.

For the mass/volume method, a core is cut into sections and weighed. The volume of each section is estimated assuming standard dimensions. We compared the use of machined cuboid blocks from a structure core, with $0.1 \mathrm{~m}$ sections from density-dedicated cores. The densitydedicated core was processed so as to minimize brine drainage, cutting the core immediately on extraction and storing each section separately in closed containers.

The liquid/solid volume method involves measuring the volume of solid and melted core sections. This method may be employed when access to a freezer laboratory is not possible. We used this method on density-dedicated cores, so we can directly compare it with the mass/volume method.

The transect method uses ice thickness, freeboard, snow thickness and density data collected along $100 \mathrm{~m}$ transects. Ice density is estimated assuming that the ice and snow along the transect is in hydrostatic balance.

\section{Density estimate with small-block mass/volume method}

The same method was used to process the two structure cores from stations 6 and 7, although environmental conditions varied at the two stations. At both stations, $2 \mathrm{~m}$ air temperature varied between $-10^{\circ} \mathrm{C}$ and $-1^{\circ} \mathrm{C}$. Warmer air could result in enhanced brine drainage from core sections that were not immediately placed in a freezer.

The ice core was placed whole in a core tube, after recording ice temperature every $0.05 \mathrm{~m}$ along the core, stored at $-22^{\circ} \mathrm{C}$ and later processed in the freezer for structure by cutting a thin section out of the center of the core. Sections were cut at $0.05 \mathrm{~m}$ intervals, or finer if required to define interfaces in the core. Rectangular blocks were cut from one half of each core section. The dimensions of these blocks were measured by caliper and each block was weighed. Density of the block was calculated as the weight divided by the volume. The density of each block is plotted as a profile in Figure 2.

The measurement error for this method is relatively high, as it is inversely related to the volume and weight of the blocks and the blocks were small. Propagation of weight and length measurement errors through our calculation gives an uncertainty bound on the density estimate. The weight measurement has accuracy of the scale $\epsilon_{\mathrm{m}}=0.01 \mathrm{~g}$. Length measurement is taken to be accurate to within $\epsilon_{\mathrm{d}}=1 \mathrm{~mm}$, to account for the possibility that calipers were not placed parallel to block sides when measuring length. We estimate measurement error for density following

$$
\frac{\epsilon_{\rho_{\mathrm{i}}}}{\rho_{\mathrm{i}}}=\frac{\epsilon_{\mathrm{d}}}{D}+\frac{\epsilon_{\mathrm{m}}}{\mathcal{M}}
$$

where $D$ is the mean block dimension and $M$ is mean segment mass. The mean ice densities with measurement uncertainty are $861 \pm 68 \mathrm{~kg} \mathrm{~m}^{-3}$ and $782 \pm 57 \mathrm{~kg} \mathrm{~m}^{-3}$ for the cores at stations 6 and 7 respectively. The dashed lines in Figure 2 show the measurement error for each block based on the actual block dimensions and weight. 

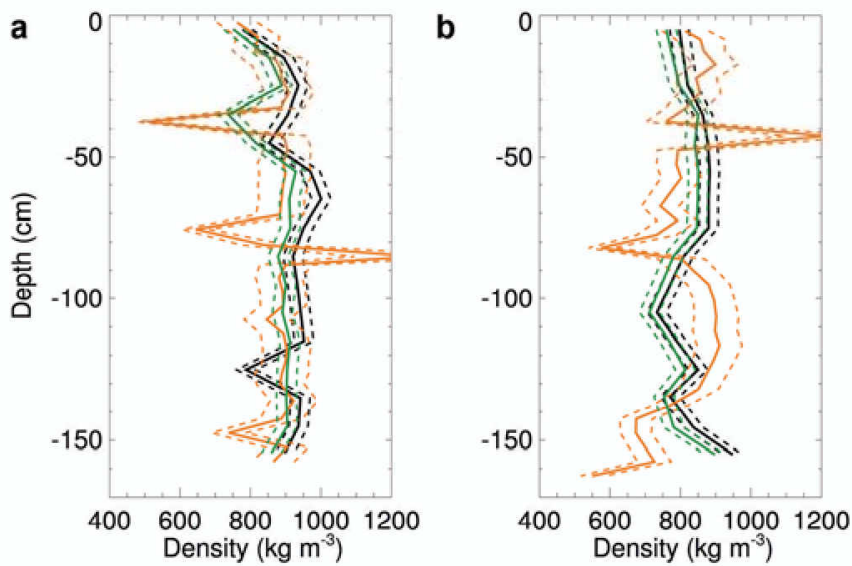

Fig. 2. Profiles of ice density from the three core-based methods for stations 6 (a) and 7 (b). Shown in green is the mass/volume method for $0.1 \mathrm{~m}$ core sections. Orange shows the mass/volume method with smaller block sizes. The liquid/solid volume method is shown in black, for the same core sections as shown in green. Dashed lines are measurement error bounds on each estimate.

The thick sections were used to identify columnar, granular and superimposed ice. The structure of the cores indicates that the ice experienced multiple rafting events, with the largest continuous columnar ice growth to $0.6 \mathrm{~m}$, and frazil or supposition ice located between rafted layers. We classify each density sample, and find mean density for columnar and granular ice at the two sites. For station 6 , granular and columnar ice have comparable density, echoing the findings of Sinha (1984).

The station 7 core had columnar ice density of $881 \pm$ $63 \mathrm{~kg} \mathrm{~m}^{-3}$, superimposed ice density of $862 \pm 65 \mathrm{~kg} \mathrm{~m}^{-3}$ and granular ice density of $728 \pm 53 \mathrm{~kg} \mathrm{~m}^{-3}$. This granular ice was found in a $1.3 \mathrm{~m}$ layer at the base of the core, unlike the station 6 core which had granular ice in thin layers between blocks of columnar ice. The granular ice at station 7 probably formed under different conditions to those at station 6. It is intriguing that this granular ice, of loose structure with large air pockets sometimes tens of centimeters in vertical length, is the reason mean ice density was substantially lower at station 7 than at station 6 .

\section{Density estimate with core section mass/volume method}

The density-dedicated ice core was sawn into $\sim 0.1 \mathrm{~m}$ sections at the point of collection, and each piece placed in a closed bucket to ensure minimal brine loss. These were stored at $-22^{\circ} \mathrm{C}$, then first processed in a freezer room. Each section's length was measured by caliper in three locations and average length used in volume calculation. To calculate volume, the sections were assumed to have a radius given by the dimensions of the corer. We also checked the core width with calipers. The sections were then weighed and returned to their container for further processing. Density for each section was calculated as weight divided by volume.

As in the block mass/volume method, uncertainty in our density calculation is estimated by error propagation. As sample sizes were larger we used a scale with accuracy $\epsilon_{\mathrm{m}}=0.1 \mathrm{~g}$.

Measurement error for density is given by

$$
\frac{\epsilon_{\rho_{\mathrm{i}}}}{\rho_{\mathrm{i}}}=\frac{\epsilon_{\mathrm{d}}}{R}+\frac{\epsilon_{\mathrm{d}}}{L}+\frac{\epsilon_{\mathrm{m}}}{M} \text {, }
$$

where $R$ is the core radius $(0.044 \mathrm{~m}), L$ is the core section length $(0.1 \mathrm{~m})$ and $M$ is the mean section mass.

The mean ice densities with measurement uncertainty are $873 \pm 28 \mathrm{~kg} \mathrm{~m}^{-3}$ and $800 \pm 28 \mathrm{~kg} \mathrm{~m}^{-3}$ for the cores at stations 6 and 7 respectively. These values agree with the estimates using the small-block mass/volume method, to within the uncertainty of the measurements.

\section{Density estimate with liquid/solid volume method}

The core sections from the density-dedicated core were placed in a warm location to melt in their closed containers. Temperature, salinity and volume of the meltwater were recorded. The density of the ice meltwater, $\rho_{\mathrm{mw}}$, was calculated using the UNESCO International Equation of State (IES 80) (Fofonoff, 1985). Ice density for each section was then calculated as

$$
\rho_{\mathrm{i}}=\rho_{\mathrm{mw}} \frac{V_{\mathrm{mw}}}{V_{\mathrm{i}}},
$$

where $V_{\mathrm{i}}$ is the volume of the core section and $V_{m w}$ is the volume of meltwater.

To estimate uncertainty in our density calculation we need an estimate of the accuracy of the meltwater density calculation, which is related to the salinity measurement error. The salinity and temperature measurement precisions were 0.1 psu and $0.1^{\circ} \mathrm{C}$ respectively. Hence the measurement uncertainty for meltwater density, $\rho_{w}$, is $\epsilon_{\rho_{w}}=0.1 \mathrm{~kg} \mathrm{~m}^{-3}$. The liquid volume $\left(V_{1}\right)$ measurement accuracy was $\epsilon_{V_{1}}=0.01 \mathrm{~L}$. Propagation of measurement errors is used to estimate uncertainty on the ice density calculation:

$$
\frac{\epsilon_{\rho_{\mathrm{i}}}}{\rho_{\mathrm{i}}}=\frac{\epsilon_{\mathrm{d}}}{R}+\frac{\epsilon_{\mathrm{d}}}{L}+\frac{\epsilon_{V_{\mathrm{i}}}}{\left|V_{1}\right|}+\frac{\epsilon_{\rho_{\mathrm{w}}}}{\left|\rho_{\mathrm{w}}\right|} .
$$

The mean ice densities with measurement uncertainty were estimated as $911 \pm 40 \mathrm{~kg} \mathrm{~m}^{-3}$ and $843 \pm 46 \mathrm{~kg} \mathrm{~m}^{-3}$ for the cores at stations 6 and 7 respectively. It appears that the meltwater volume method returns a higher density estimate than the mass/volume method (Fig. 2).

The difference in density found with this method compared to the mass/volume method with the same core is $5 \%$. With a sample of two cores it is not possible to determine whether this difference is consistent between the two methods. If it is a consistent feature, the likely explanation will be linked to brine drainage in the containers used to store $0.1 \mathrm{~m}$ sections. There was ice present - possibly frozen brine - on the floor of the containers when measuring the ice samples.

\section{Density estimate from $100 \mathrm{~m}$ transect data}

By assuming the ice along a $100 \mathrm{~m}$ drillhole transect is in hydrostatic balance the density of the ice can be calculated as

$$
\rho_{\mathrm{i}}=\rho_{\mathrm{w}} \frac{Z_{\mathrm{i}}-Z_{\mathrm{f}}}{Z_{\mathrm{i}}}-\rho_{\mathrm{s}} \frac{z_{\mathrm{s}}}{Z_{\mathrm{i}}},
$$

where $\rho_{i}, \rho_{w}$ and $\rho_{s}$ are bulk mean densities for ice, sea water and snow. The mean ice thickness is $Z_{\mathrm{i}}$, mean ice freeboard $z_{\mathrm{i}}$, and $z_{\mathrm{s}}$ is mean snow thickness.

Along the two transects (on stations 6 and 7 respectively; Fig. 3) mean snow depth was 0.28 and $0.52 \mathrm{~m}$, mean ice thickness was 1.73 and $4.87 \mathrm{~m}$ and mean freeboard was 0.10 and $0.29 \mathrm{~m}$.

Snow density was measured at five snow pits on station 6 and three snow pits on station 7 . These pits were located at 0,50 and $100 \mathrm{~m}$ along the transects (there being two transects originating at the same point on station 6). At each 
a
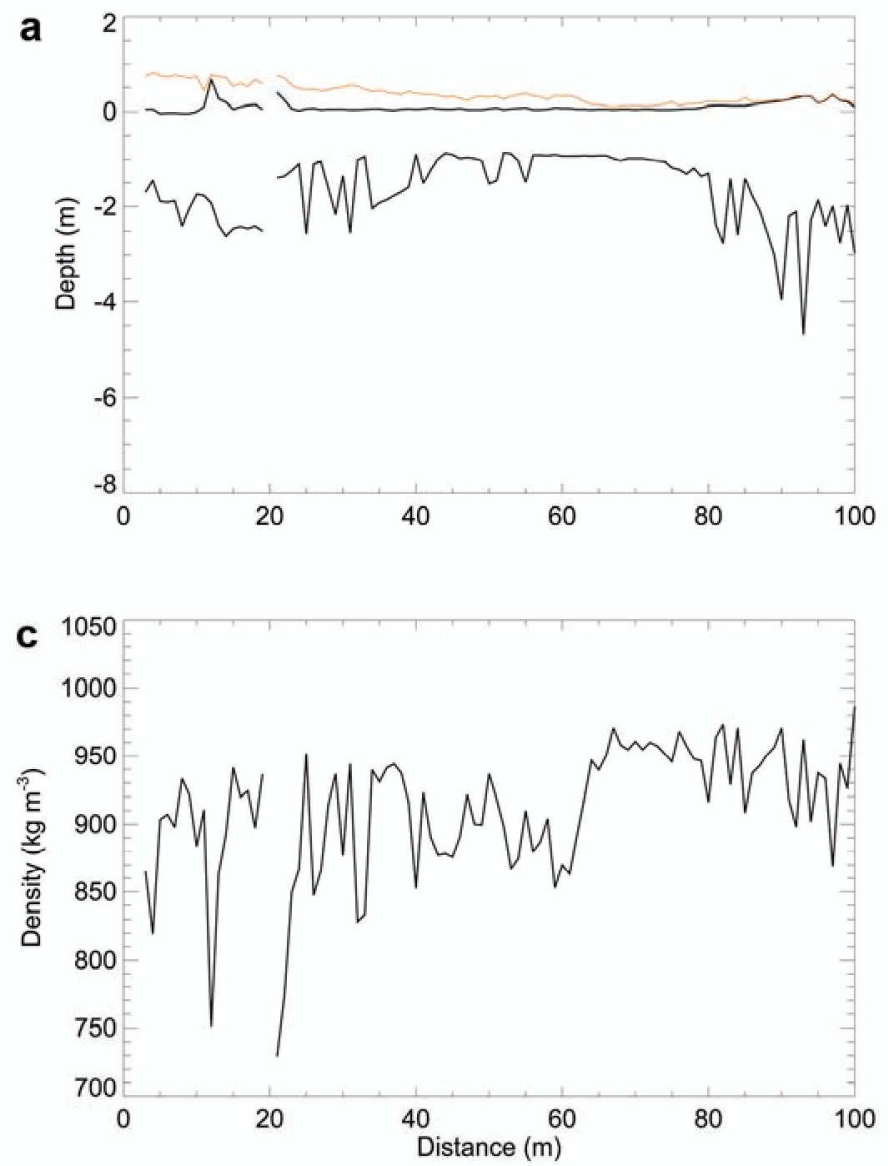
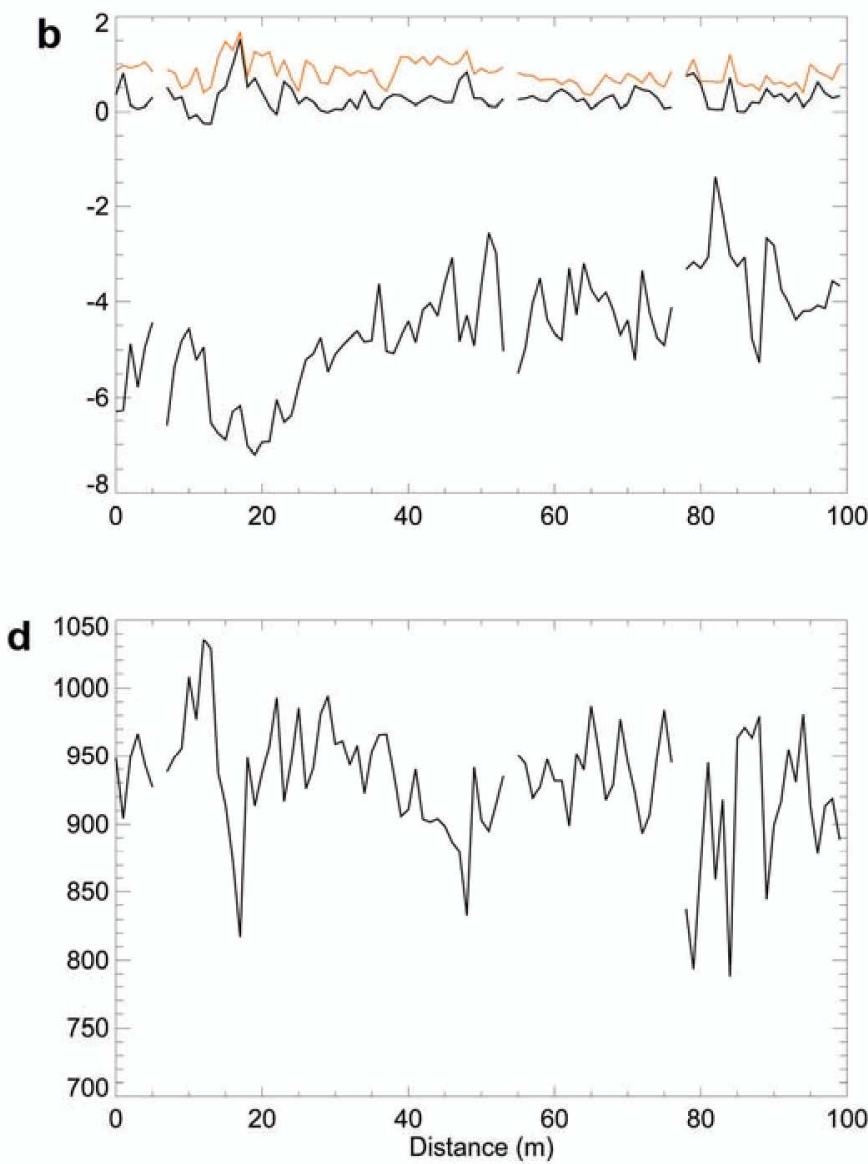

Fig. 3. $100 \mathrm{~m}$ transects at ice stations $6(\mathrm{a}, \mathrm{c})$ and 7 (b, d). Ice draft and freeboard are plotted in black, and snow surface is plotted in orange. (c, d) Ice density estimated at each drillhole.

pit, snow density was measured with the known volume method, taking $0.03 \mathrm{~m}$ high samples through the total snow depth. A total of 56 samples were recorded.

Mean snow density at both ice stations was $344 \mathrm{~kg} \mathrm{~m}^{-3}$, with a standard deviation of $60 \mathrm{~kg} \mathrm{~m}^{-3}$ across the 56 density measurements. The standard error on the mean density recorded at the eight snow pits is $22 \mathrm{~kg} \mathrm{~m}^{-3}$.

Water density was calculated from profiles of water temperature and conductivity taken under the ice with the TEOS-10 equation of state for sea water (Feistel and others, 2010; Wright and others, 2010). At both ice stations several casts were taken through core holes along or near the $100 \mathrm{~m}$ transect. We used the mean density in the upper $10 \mathrm{~m}$ of the ocean, as ice does not reach below this depth along the transect. Upper ocean density varies in space and time under sea ice. Ice growth results in brine rejection and dense water plumes, and ice melt provides buoyant water. At ice station 6 we found a relatively stable upper $10 \mathrm{~m}$ water density of $1028 \mathrm{~kg} \mathrm{~m}^{-3}$. The near-surface water profiles suggest ice growth was occurring as salinity is increasing towards the ice.

At ice station 7, we believe bottom melt was occurring. Ocean profiles from different times showed fresh buoyant water near the surface, and the top $10 \mathrm{~m}$ experienced variable water densities from profile to profile. The upper $10 \mathrm{~m}$ mean ocean density was between 1025 and $1028 \mathrm{~kg} \mathrm{~m}^{-3}$. Ice melt acts to freshen and lighten surface waters; however, this water is mixed with lower water, restoring density to $1028 \mathrm{~kg} \mathrm{~m}^{-3}$. We use a water density of
$1028 \mathrm{~kg} \mathrm{~m}^{-3}$ to calculate ice density, as buoyant fresh water was only observed sporadically during ice station 7 .

From the snow-depth, snow-density, ice-thickness and ice-freeboard data collected along $100 \mathrm{~m}$ transects we find bulk (mean) densities of the ice to be 915 and $930 \mathrm{~kg} \mathrm{~m}^{-3}$ at stations 6 and 7 respectively. The standard deviation of the densities measured at all drillholes is 42 and $44 \mathrm{~kg} \mathrm{~m}^{-3}$ at stations 6 and 7 . These bulk density estimates are $3-10 \%$ higher than the sea-ice density estimated from ice cores. The values are also high when compared to previous measurements of ice density reported by Timco and Frederking (1996) and Buynitskiy (1967). A similar finding is reported by Price and others (2014).

Uncertainty due to measurement error can be estimated with an error propagation analysis. We take the uncertainty in water density to be $3 \mathrm{~kg} \mathrm{~m}^{-3}$, as this is the maximum observed water density deviation from $1028 \mathrm{~kg} \mathrm{~m}^{-3}$. The contribution of water density uncertainty to the total uncertainty is negligible, being an order of magnitude smaller than the other sources of uncertainty. The measurement error on ice thickness, freeboard and snow depth is $0.01 \mathrm{~m}$. We can identify a measurement error for snow density using scale precision and volume measurement error; however, this will not be meaningful to the bulk ice density error. The snow density error should represent the uncertainty in the representation of bulk snow density provided by the snow pits. We could take the standard error on the mean of bulk snow density across all snow pits, $22 \mathrm{~kg} \mathrm{~m}^{-3}$, as a measure of this. Snow density uncertainty represents a $21 \%$ contribution to uncertainty in ice density. 
Freeboard measurement presents the largest uncertainty to the ice density, with an average $30 \%$ contribution. Snow depth and ice thickness measurement errors contribute $17 \%$ and $1 \%$ respectively. The contributions of snow depth, ice thickness and freeboard measurement errors to the bulk density across the entire transect are two orders of magnitude lower, as the measurement error should be taken as the standard error on the mean over the 101 measurements. The largest source of measurement uncertainty for bulk ice density estimated with the transect method is due to the uncertainty in snow density.

\section{DISCUSSION OF ERRORS IN ESTIMATING ICE DENSITY}

The measurement error for core-based methods of estimating ice density is straightforward to identify, as component measurement errors are known and can be propagated through the calculations. It should be noted that large block sizes, of $>0.1 \mathrm{~m}$ length when entire $0.1 \mathrm{~m}$ diameter core sections are used, are required to reduce the accuracy of the density estimate to $<1 \%$. There is also an indication that brine drainage might cause mass/volume density estimates to be at least $5 \%$ too low, even though care is taken to move cores quickly to a freezer. This is in agreement with Timco and Frederking (1996) who qualitatively identify a low bias in density measurements from samples experiencing brine drainage. Comparison of mass/ volume and liquid/solid volume methods on the same cores suggests an error of $5 \%$ due to brine drainage. Note that additional brine may have drained while the ice core was cut to $0.1 \mathrm{~m}$ lengths. This is not accounted for in this $5 \%$ bias estimate.

We found values for bulk ice density from $100 \mathrm{~m}$ transects to be higher than core ice density. Brine drainage from cores might account for part of the discrepancy between the methods. From Timco and Frederking (1996, table 1), we can estimate the maximum impact of brine drainage on density for methods that ensure brine was not lost, by comparing measurements of sea-ice density above and below the waterline. The largest density difference above and below the waterline in such a case is $20 \%$, which suggests the maximum impact of brine drainage on density measurements is of the order $20 \%$. Such an error could explain the difference between transect and core methods. However, we believe that the brine drainage actually experienced was lower as there are other possible sources of error in our density estimates.

A large uncertainty in the hydrostatic balance approach (Eqn (5)) is in snow density. In order to explain the different densities determined from core and transects by snow density alone, the snow density needs to be $>50 \%$ lower than the estimate used. This is more than double the standard error on the mean of our bulk density estimates.

It is also possible that the snow depth measurement along a $100 \mathrm{~m}$ transect is not representative of the snow load in the vicinity of the transect. Grids of snow depth at $1 \mathrm{~m}$ spacing were recorded for a $100 \mathrm{~m} \times 100 \mathrm{~m}$ box next to each transect. From these we find that the transect on station 7 was representative of the wider-area snow depth. The transect at station 6 had $55 \%$ of the snow depth in the wider area. If we use the wider-area snow depth in our density estimate, we find a density comparable to the core methods. Hence it is possible that misrepresentation of snow depth can explain the difference in ice density estimates, though we suspect this is not the case for ice station 7 .

It might be questioned whether ice is in isostatic balance over $100 \mathrm{~m}$. For example, Doble and others (2011) found deformed ice out of isostatic balance for $>300 \mathrm{~m}$, in the vicinity of an Arctic first-year ice ridge. The ice pack in the region of ice stations 6 and 7 was convergent, hence we can expect the length scale for isostatic balance to be relatively long since convergent ice will bow under the imposed horizontal stress.

Loading of the ice with equipment can suppress the freeboard and affect density calculations. Price and others (2014) determine that personal and drill equipment can result in up to a $5 \mathrm{~kg} \mathrm{~m}^{-3}$ overestimate in ice density. We observed negative freeboard at ice station 6 in the vicinity of the ship, indicating that freeboard measurements were potentially contaminated by ship loading on the ice.

The difference between core and transect methods is most likely related to a combination of brine drainage and inappropriateness of the assumption of hydrostatic balance over $100 \mathrm{~m}$. We suspect that ship loading on the ice impacted the transect density estimates. This leads us to question the use of in situ transect data collected in the vicinity of ships for estimating ice density.

\section{FINDINGS AND FUTURE WORK}

We have compared ice density estimates with several core methods and from transects in the East Antarctic during the winter-to-spring transition. It is striking that the ice density estimated from ice cores is less than that used to retrieve ice thickness by remote sensing. Yet density estimated from transects is high compared to bulk sea-ice density values published elsewhere.

Ice cores provide ice density information, albeit with errors that depend upon the method used. To reduce these errors to acceptable levels, several ice cores could be used. The values for mean ice density given by the Timco and Frederking (1996) review are from a relatively small sample, and in many cases methodology is not well documented and measurement errors unknown. If the measurement errors are as large as our small-block method $(\sim 8 \%)$ over ten cores the standard error on the mean is $<1 \%$. Even if measurement error is reduced to acceptable levels, core-based ice density estimates are biased. Underestimation of ice density due to brine drainage can be significant, and in this study was found to be $>1 \%$. It is possible that this explains a substantial portion of the difference between core and transect methods.

A pertinent question is whether the sample of ice-core density estimates available to us is representative of spatial and temporal variability in sea-ice density. We did not set out to address this question. However, the fact that low densities were found consistently across the cores, yet with $\sim 70 \mathrm{~kg} \mathrm{~m}^{-3}$ difference between two sites, in similar ice type, does demonstrate that a single core is not representative of regional ice density. To our knowledge, such spatial variability in sea-ice density has not been investigated.

One way to estimate bulk ice density without introducing the bias prevalent in core extraction is the use of ice and snow transect data. The use of $100 \mathrm{~m}$ transect data to estimate ice density is unreliable without a reasonable estimate of snow density. In our case studies we would have to increase snow density to unrealistically high values to account for the discrepancy between transect- and core- 
based ice density estimates. Measurement errors on the variables (snow density, snow depth and ice thickness) in the hydrostatic balance equation are not likely to account for the high density bias we found. This suggests there is an alternate reason for the overestimate in ice density using transect data. It may be flawed to consider the ice pack to be in hydrostatic balance over $100 \mathrm{~m} .100 \mathrm{~m}$ transects may not provide sufficient representation of snow depth, freeboard and draft over length scales on which the ice sheet is in hydrostatic balance. Longer transects or grid surveys, further from ships parked in the ice, are needed to accurately measure mean freeboard and ice density. We also need to identify the maximum length scale over which sea ice exhibits hydrostatic balance to use this method.

\section{ACKNOWLEDGEMENTS}

This research was supported by Australian Antarctic Science grants No. 4072 and No. 4073, and US National Science Foundation Office of Polar Programs grant 1023662. The International Space Science Institute, Bern, Switzerland, is thanked for supporting scientific collaborations of this study through grant No. 245. Snow-pit and depth data were collected along transects by Rob Massom, Takenobu Toyota and Barry Giles. Magnaprobe snow depth data were collected by Ted Maksym. A large number of crew and expeditioners participated in collecting the transect data. We are very appreciative of the efforts of Capt. Murray Doyle and the crew of the Aurora Australis during the SIPEX-II expedition.

\section{REFERENCES}

Buynitskiy VK (1967) Structure, principal properties, and strength of Antarctic sea ice. Sov. Antarct. Exped. Inf. Bull., 6(6), 504-510

Cox GFN and Weeks WF (1983) Equations for determining the gas and brine volumes in sea-ice samples. I. Glaciol., 29(102), 306-316

Doble MJ, Skouroup H, Wadhams P and Geiger CA (2011) The relation between Arctic sea ice surface elevation and draft: a case study using coincident AUV sonar and airborne scanning laser. J. Geophys. Res., 116(C8), COOE03 (doi: 10.1029/ 2011JC007076)

Feistel R and 9 others (2010) Numerical implementation and oceanographic application of the thermodynamic potentials of liquid water, water vapour, ice, seawater and humid air - Part 1: background and equations. Ocean Sci., 6(3), 633-677 (doi: 10.5194/os-6-633-2010)
Fofonoff NP (1985) Physical properties of seawater: a new salinity scale and equation of state for seawater. J. Geophys. Res., 90 (C2), 3332-3342 (doi: 10.1029/JC090iC02p03332)

Giles KA, Laxon SW and Worby AP (2008) Antarctic sea ice elevation from satellite radar altimetry. Geophys. Res. Lett., 35 (3), L03503 (doi: 10.1029/2007GL031572)

Kurtz NT and Markus T (2012) Satellite observations of Antarctic sea ice thickness and volume. J. Geophys. Res., 117(C8), C08025 (doi: 10.1029/2012JC008141)

Kwok R and Cunningham GF (2008) ICESat over Arctic sea ice: estimation of snow depth and ice thickness. J. Geophys. Res., 113(C8), C08010 (doi: 10.1029/2008JC004753)

Price D, Rack W, Haas C, Langhorne PJ and Marsh O (2013) Sea ice freeboard in McMurdo Sound, Antarctica, derived by surfacevalidated ICESat laser altimeter data. J. Geophys. Res., 118(7), 3634-3650 (doi: 10.1002/jgrc.20266)

Price D, Rack W, Langhorne PJ, Haas C, Leonard G and Barnsdale K (2014) The sub-ice platelet layer and its influence on freeboard to thickness conversion of Antarctic sea ice. Cryos. Discuss., 8 (1), 999-1022 (doi: 10.5194/tcd-8-999-2014)

Sinha NK (1984) Uniaxial compressive strength of first-year and multi-year sea ice. Can. J. Civil Eng., 11(1), 82-91

Timco GW and Frederking RMW (1996) A review of sea ice density. Cold Reg. Sci. Technol., 24(1), 1-6 (doi: 10.1016/0165-232X (95)00007-X)

Timco GW and Weeks WF (2010) A review of the engineering properties of sea ice. Cold Reg. Sci. Technol., 60(2), 107-129 (doi: 10.1016/j.coldregions.2009.10.003)

Urabe $\mathrm{N}$ and Inoue $\mathrm{M}$ (1986) Mechanical properties of Antarctic Sea ice. In Chung IS ed. Proceedings of the 5th International Offshore Mechanics and Arctic Engineering (OMAE) Symposium, 13-18 April 1986, Tokyo, Japan, Vol. 4. American Society of Mechanical Engineers, New York

Worby AP, Geiger CA, Paget MJ, Van Woert ML, Ackley SF and DeLiberty TL (2008) Thickness distribution of Antarctic sea ice. J. Geophys. Res., 113(C5), C05\$92 (doi: 10.1029/ 2007JC004254)

Wright DG and 9 others (2010) Numerical implementation and oceanographic application of the thermodynamic potentials of liquid water, water vapour, ice, seawater and humid air - Part 2: the library routines. Ocean SCi., 6(3), 695-718 (doi: 10.5194/ os-6-695-2010)

Xie H, Tekeli AE, Ackley SF, Yi D and Zwally HJ (2012) Sea ice thickness estimations from ICESat altimetry over the Bellingshausen and Amundsen Seas, 2003-2009. J. Geophys. Res., 118 (5), 2438-2453 (doi: 10.1002/jgrc.20179)

Zwally HJ, Yi D, Kwok R and Zhao Y (2008) ICESat measurements of sea ice freeboard and estimates of sea ice thickness in the Weddell Sea. J. Geophys. Res., 113(C2), C02S15 (doi: 10.1029/ 2007JC004284) 